\title{
The Effect of Innovation Capabilities of Health Care Organizations on the Quality of Health Information Technology: Model Development With Cross-sectional Data
}

\author{
Moritz Esdar $^{1}$, MA; Ursula Hübner ${ }^{1}$, PhD; Johannes Thye ${ }^{1}$, MA; Birgit Babitsch², MPH, PhD; Jan-David Liebe ${ }^{1,3}$, \\ $\mathrm{PhD}$ \\ ${ }^{1}$ Health Informatics Research Group, Faculty of Business Management and Social Sciences, University of Applied Sciences Osnabrueck, Osnabrueck, \\ Germany \\ ${ }^{2}$ Institute of Health and Education, New Public Health, Osnabrück University, Osnabrueck, Germany \\ ${ }^{3}$ Institute of Medical Informatics, UMIT - Private University for Health Sciences, Medical Informatics and Technology, Hall in Tyrol, Austria
}

Corresponding Author:

Ursula Hübner, $\mathrm{PhD}$

Health Informatics Research Group

Faculty of Business Management and Social Sciences

University of Applied Sciences Osnabrueck

Caprivistr 30A

Osnabrueck, 49076

Germany

Phone: 495419692012

Email: u.huebner@hs-osnabrueck.de

\begin{abstract}
Background: Large health organizations often struggle to build complex health information technology (HIT) solutions and are faced with ever-growing pressure to continuously innovate their information systems. Limited research has been conducted that explores the relationship between organizations' innovative capabilities and HIT quality in the sense of achieving high-quality support for patient care processes.
\end{abstract}

Objective: The aim of this study is to explain how core constructs of organizational innovation capabilities are linked to HIT

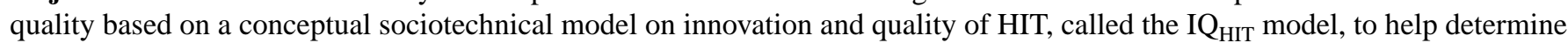
how better information provision in health organizations can be achieved.

Methods: We designed a survey to assess various domains of HIT quality, innovation capabilities of health organizations, and context variables and administered it to hospital chief information officers across Austria, Germany, and Switzerland. Data from 232 hospitals were used to empirically fit the model using partial least squares structural equation modeling to reveal associations and mediating and moderating effects.

Results: The resulting empirical $\mathrm{IQ}_{\mathrm{HIT}}$ model reveals several associations between the analyzed constructs, which can be summarized in 2 main insights. First, it illustrates the linkage between the constructs measuring HIT quality by showing that the professionalism of information management explains the degree of HIT workflow support $\left(R^{2}=0.56\right)$, which in turn explains the perceived HIT quality $\left(R^{2}=0.53\right)$. Second, the model shows that HIT quality was positively influenced by innovation capabilities related to the top management team, the information technology department, and the organization at large. The assessment of the model's statistical quality criteria indicated valid model specifications, including sufficient convergent and discriminant validity for measuring the latent constructs that underlie the measures of HIT quality and innovation capabilities.

Conclusions: The proposed sociotechnical $\mathrm{IQ}_{\mathrm{HIT}}$ model points to the key role of professional information management for HIT workflow support in patient care and perceived HIT quality from the viewpoint of hospital chief information officers. Furthermore, it highlights that organizational innovation capabilities, particularly with respect to the top management team, facilitate HIT quality and suggests that health organizations establish this link by applying professional information management practices. The model may serve to stimulate further scientific work in the field of HIT adoption and diffusion and to provide practical guidance to managers, policy makers, and educators on how to achieve better patient care using HIT. 
(JMIR Med Inform 2021;9(3):e23306) doi: 10.2196/23306

\section{KEYWORDS}

organizational innovation; health information management; organizational culture; diffusion of innovation; hospital information systems; organizational change management

\section{Introduction}

\section{Background}

Discussions on health information technologies (HITs) in research and practice have increasingly shifted from dealing with the question of if digital solutions are worth investing in $[1,2]$ to questions on how higher degrees of successful digitalization can be achieved [3-6] and how HIT improves processes and outcomes [7-9]. Although the term HIT has been used and defined in various ways, we understand it to encompass the organization's electronic information technologies that health care professionals use to support the care process [7]. These include, but are not limited to, electronic medical records, health information exchange systems, computerized provider order entry, clinical decision support systems, and the related hardware (excluding medical devices) and their integration with each other.

It has been repeatedly demonstrated that large health organizations often struggle to adopt high-quality and modern HIT solutions and are challenged with increasingly shorter innovation cycles of these technologies [10-15]. The fact that there is considerable variation in the adoption and quality of HIT between organizations within and across countries points to the importance of focusing on the organizations themselves in terms of their inner capabilities with regard to managerial skills, the promotion of HIT use, project execution, and innovation promotion [16-18]. Although a wide range of general facilitating factors of successful HIT adoption have been acknowledged in several theoretical frameworks [19-24] and various systematic literature reviews [3,12,25-28], little is known about the exact constituents of capabilities of health care organizations to innovate in particular and how they affect not only the adoption of HIT but also their quality. Insights about this relationship could prove valuable for guiding managers, policy makers, and educators toward promoting and developing organizational behavior that facilitates better HIT use, which in turn might lead to improved clinical outcomes [29].

\section{HIT Quality and Innovation Capabilities}

HIT adoption is most often understood as the implementation, that is, the introduction of an application, and its acceptance and use in an organization and many adoption studies focus on specific functionalities or applications [12,21,27]. However, the complexity of organization-wide HIT solutions is usually far greater and requires the incorporation of many different facets of the organization's information system [30-33]. In addition, when extending the scope from adoption to the quality of HIT, even more aspects need to be incorporated as quality requirements are typically considered to incorporate not only various technical layers (eg, data and information, functions, hardware, interoperability) to support clinical care processes but also features of information management and the perceived quality of the IT systems [17,23,34,35]. Thus, in our study, we focus on HIT quality rather than mere adoption and consider it to be composed of the following 3 principal domains: HIT information management, HIT workflow support, and perceived HIT quality:

- HIT information management encompasses the full spectrum of strategic, tactical, and operational management tasks to build and operate an organization's information system [34,36]. Management practices are deemed to be essential preconditions for realizing the potential of HIT [37], especially those executed by the information technology (IT) department $[38,39]$ and those that involve systematic clinical user participation $[40,41]$.

- HIT workflow support refers to the degree to which an organization has implemented the information technologies needed to support patient care processes. This encompasses the availability of electronic patient data across various care processes as discussed by Liebe et al [42], the availability of clinical applications (eg, electronic medical records, computerized provider order entry, and clinical decision support systems), their integration with one another, and accommodation of hardware solutions. This confluence of technical factors has been discussed as indicative of structural and process quality $[17,43]$.

- Finally, HIT quality manifests itself not only in the technical quality of HIT but also in the subjective assessment of the implemented IT solutions that is hereinafter referred to as the perceived HIT quality.

In addition to HIT quality, there is also little understanding about the identification and effect of the organization's capabilities to innovate; however, as van Gemert-Pijnen et al [44] emphasize, many HIT innovations might fail as a result of disregarding the interdependencies between technology and its organizational and cultural environment. In our understanding, innovation capabilities (ICs) refer to the culture regarding HIT at various organizational levels that reflect its ability to innovate, that is, the ability to adopt new HIT solutions (or to renew the existing ones) that enhance the quality of information provision in clinical care processes. These capabilities refer to latent phenomena, that is, they are inherently difficult to capture, as they are expressions of a commonly shared attitude in social networks that leads to certain sets of corresponding behaviors $[45,46]$. In light of the semantic variations and inconsistent definitions of related phenomena, scholars have pointed to the need for further work to examine this construct and its measurement [47-49]. The lack of measurements also implies that there are few studies that provide empirically tested claims regarding the effect of an organization's ICs on HIT adoption or quality $[49,50]$. 


\section{Conceptual Model and Study Objectives}

Only a few theoretical frameworks incorporate the peculiarities and complexity of organization-wide HIT solutions in a way that allows for an assessment of its quality and success $[23,24,34]$. Others acknowledge the facilitating role of domains comparable with ICs $[19,20]$; however, there is no framework that puts the spotlight on the interrelationship between these 2 constructs and how they might enable better information provision in the care processes. Correspondingly, there is a need for validated measurement scales within such a framework to put its implicit hypotheses into the empirical test. Although some studies have begun to derive related scale sets [51-53], they are not yet ready to measure the full picture of the relationship between the 2 domains. In addition, the few that attempted to test more complex relationships between related constructs have limitations, particularly regarding small sample sizes and rather narrow outcome measures of HIT quality [54-56].
To investigate the sociotechnical interrelationships between ICs and HIT, we propose an initial conceptual model, that is, the $\mathrm{IQ}_{\mathrm{HIT}}$ (innovation and quality of HIT) model (Figure 1). It rests on the underlying assumption of a directional process of antecedents and consequences of HIT as was similarly conceptualized in studies by Leidner et al [54] and Greenhalgh et al [57]. This is reflected in the assumption that HIT information management affects the degree of HIT workflow support that then determines the perceived HIT quality. Furthermore, these domains can be assumed to be influenced by an organization's ICs. In addition, internal structural characteristics such as the organization's size, teaching status, and ownership as well as external influences in terms of national health policies and legal regulations need to be accounted for as possible covariates in the model, as both have been shown to be significantly associated with HIT use [58-61].

On the basis of this model, the research goal was to empirically test and explain how health organizations' ICs are linked to HIT quality.

Figure 1. Initial conceptual innovation and quality of health information technology model of the layered relationship between innovation capabilities, health information technology quality, and covariates. HIT: health information technology.

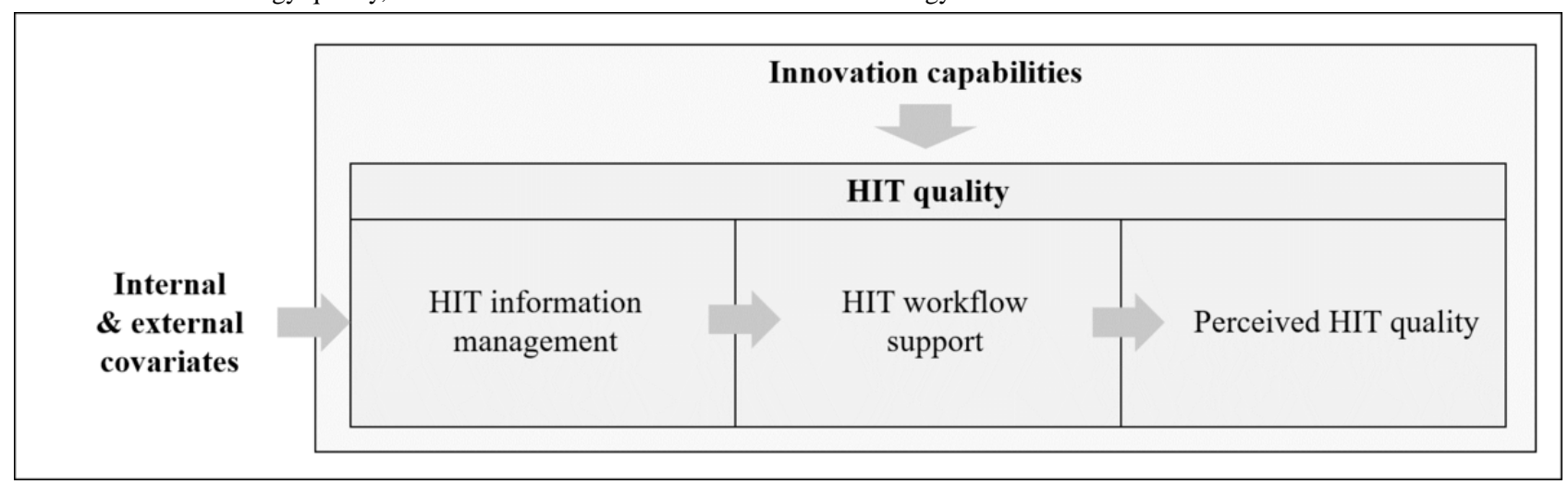

\section{Methods}

\section{Data Collection}

Serving as empirical input for the model, data from chief information officers (CIOs) as hospital representatives were obtained. Hospitals are particularly interesting because of both the complexity of their IT and their organizational environment. We chose CIOs as our target group because they have the best oversight of the entirety of the IT landscape and top management issues [62,63]. We included Austrian, German, and Swiss hospitals in our target population to control for external influences in terms of different national health policies. The questionnaire and its constructs were based on the redevelopment and refinement of previous surveys and included a total of 188 question items (Multimedia Appendices 1 and 2) [64]. The final questionnaire was pretested by 5 hospital CIOs, 10 researchers (comprising health IT experts, statisticians, and 1 psychologist), and 1 clinician to evaluate whether the question items were understandable and answerable and whether they were sufficiently precise to measure the organization's information system. This led to some minor adjustments of item scales (response options), changes in the wording of items, and a few supplementary definitions.
Email addresses of 1669 CIOs were compiled through internet and telephone searches. The CIOs were responsible for 2324 hospitals (92\% of all 2542 hospitals across Austria, Germany, and Switzerland). Data collection took place during the first half of 2017 via a web-based survey. Of the 1669 emails sent, 1499 had come through and 251 CIOs participated (17\% response rate)-19 answers were discarded because of incompleteness (ie, the respondent did not finish the survey or sections were left out). The descriptive results were made available in 2018 [65], and as an incentive for participation, CIOs were offered access to a web-based benchmarking dashboard that allowed them to compare their hospital with peer groups [66].

\section{Modeling and Data Analysis}

We applied structural equation modeling (SEM) to test various interrelationships between constructs. Specifically, we chose partial least squares structural equation modeling as it is tolerant of the use of categorical data and allows for including reflective measurement models (ie, manifest indicators reflect the latent construct), formative measurement models (ie, manifest indicators form the latent construct), and single-item scales without identification problems [67]. 


\section{Specification of the Measurement Models}

We operationalized each of the 5 domains in the conceptual model (Figure 1), with a total of 10 constructs (Table 1). All items and scales associated with these constructs are detailed in Multimedia Appendices 1 and 2.

Table 1. Overview of the constructs used to operationalize the domains of the conceptual innovation and quality of health information technology model.

\begin{tabular}{|c|c|c|c|}
\hline Domains & Constructs & & \\
\hline \multicolumn{4}{|l|}{ HIT $^{\mathbf{a}}$ quality } \\
\hline HIT information management & Professionalism of information management & Clinical $\mathrm{IT}^{\mathrm{b}}$ agents & N/A ${ }^{c}$ \\
\hline HIT workflow support & $\begin{array}{l}\text { Workflow composite score including techni- } \\
\text { cal descriptors and care processes }\end{array}$ & N/A & N/A \\
\hline Perceived HIT quality & Perceived HIT workflow support & $\begin{array}{l}\text { Overall goodness of informa- } \\
\text { tion provision }\end{array}$ & N/A \\
\hline Innovation capabilities & $\begin{array}{l}\text { Innovation capability: top management team } \\
\text { support }\end{array}$ & $\begin{array}{l}\text { Innovation capability of the } \\
\text { information technology depart- } \\
\text { ment }\end{array}$ & $\begin{array}{l}\text { Organization-wide innovation } \\
\text { capability }\end{array}$ \\
\hline Covariates & Structural characteristics & Country & N/A \\
\hline
\end{tabular}

${ }^{\mathrm{a}} \mathrm{HIT}$ : health information technology.

${ }^{\mathrm{b}}$ IT: information technology.

${ }^{\mathrm{c}}$ N/A: not applicable.

\section{HIT Quality}

HIT information management was operationalized using 2 constructs. First, we applied a construct that captures the degree of professionalism of information management (PIM) in health care in terms of the regularity of 15 management key tasks and practices, as proposed by Thye et al [36]. As PIM consists of 3 latent and correlated subcomponents (strategic, tactical, and operational information management), we incorporated it as a reflective higher order model with PIM as the higher order construct and the 3 subcomponents as the lower order constructs using the repeated indicator approach [68]. Second, to reflect institutionalized user participation, we included the formal appointment of clinical IT agents as a reflective measurement model with 2 underlying items (one referring to physicians and the other one to nurses).

HIT workflow support can be theorized as being constituted by the descriptors data and information, IT functions, integration, and distribution of data and IT functions [17]. These 4 descriptors are the central building blocks of the Workflow Composite Score (WCS), an aggregated score that proved to be reliable and valid in measuring the degree of HIT supported patient care in core clinical processes $[17,43,65]$ : ward rounds to reflect diagnostic and therapeutic decision making at the bedside, presurgery and postsurgery processes that reflect the information flow between departments, and admission and discharge as core interface processes between outpatient and inpatient care. The WCS comprises 146 items grouped along these 5 clinical processes and the 4 descriptors (Multimedia Appendix 2). We included it in the SEM analysis as a single-item scale, as its composite structure was largely predefined in previous studies $[17,65]$.

Perceived HIT quality was measured using the 2 constructs. First, we asked the CIOs to grade the HIT workflow support (perceived HIT workflow support) in all 5 aforementioned clinical care processes separately and included the resulting indicators in a reflective measurement model. Second, we asked for a concluding assessment (single-item scale) of the overall goodness of information provision, that is, the organization's general ability to provide the right information, at the right time, at the right place, for the right persons, and in the right quality to support patient care processes. This indicator was applied in a previous study [38].

\section{Innovation Capabilities}

We investigated this domain and the underlying constructs across the 2 preceding surveys [38,52]. The initial exploratory study on this topic pointed to a latent construct, represented by 5 items that describe the top management team (TMT) support and the organization-wide innovation culture with regard to HIT [52]. A second study signified that the ICs relating to the IT department could be considered as another separate component [38]. To explore the emerging constructs in greater depth, we added 9 items to capture additional details on the TMT support and the organization-wide innovation culture and 6 additional items that refer to the IT department. An exploratory factor analysis using the unweighted least squares estimation and oblique factor rotation was computed, which resulted in a 3-factor structure that reflected ICs at the TMT level (IC TMT), ICs at the IT department level (IC ITD), and ICs at the organization-wide level (IC OW). For SEM, the underlying items were then included in 3 reflective measurement models. A total of 4 items with low outer loadings $(<0.50)$ were removed to establish sufficient convergent and discriminant validity.

\section{Covariates}

A total of 2 covariates were included in the model. First, to control for well-known structural characteristics, we included a formative measurement model that was composed of the hospital size (bed count) and its teaching status. Second, the country was included as a single-item scale to account for 
external conditions. Austrian and Swiss hospitals were pooled to obtain more balanced group sizes.

\section{Specification of the Structural Model}

The specifications of the structural model resulted from a step-wise build-up of testing the direct and mediated effects along the components of the conceptual model. Each step was thereby rooted in findings from studies that suggest individual linkages between the constructs, which we summarized into a set of 12 theoretical assumptions (Table 2). On the basis of these assumptions, we deduced one or more hypotheses for specifying the structural equation model paths. 
Table 2. Theoretical assumptions and corresponding hypotheses guiding the structural model specification.

Assumption
The PIM ${ }^{\mathrm{a}}$ might be linked to HIT ${ }^{\mathrm{b}}$ workflow support
H1: PIM has a positive effect on the $\mathrm{WCS}^{\mathrm{c}}$
Formal participation in terms of the appointment of clinical $\mathrm{IT}^{\mathrm{d}}$ agents might results from PIM practices
and might lead to better HIT workflow support
and might lead to better HIT workflow support

- H2: The effect of PIM on the WCS is partly mediated by clinical IT agents Exemplary study

There likely is a direct link between the technical and the perceived quality of HIT workflow support

- H3: The WCS has a positive effect on the perceived HIT workflow support Ammenwerth et al (2006) [69], Avgar et al (2012) [70], Bradley et al (2012) [71], Winter et al (2011) [72]

Cresswell and Sheikh (2013) [12], Liebe et al (2018) [42], Potts et al (2011) [73], Sligo et al (2017) [26]

Hadji and Degoulet (2016) [74], Hübner (2015) [75], Yusof et al (2008) [23]

- H4: The WCS has a positive effect on the overall goodness of information provision

The perceived quality of HIT is likely linked to the perceived goodness of information provision

Gorla et al (2010) [76], Suki (2012) [77]

- H5: Perceived HIT workflow support has a positive effect on the overall goodness of information provision

A top management team that is capable and willing to innovate might facilitate an innovation-friendly culture throughout the organization, including the IT department

Abdekhoda et al (2015) [78], Carpenter et al (2004) [79], Laukka et al [80]

- H6: Innovation capability: top management team support has a positive effect on organization-wide innovation capability

- H7: Innovation capability: top management team support has a positive effect on the innovation capability of the IT department

The tasks and procedures that manifest PIM might also be facilitated by an innovation-friendly top management team

- H8: Innovation capability: top management team support has a positive effect on PIM

Innovation capabilities of the top management team and the IT department might determine the degree of HIT workflow support

- H9: Innovation capability: top management team support has a positive effect on the WCS

- H10: Innovation capability of the IT department has a positive effect on the WCS

The ability of the IT department to innovate might be linked to information management practices

- H11: Innovation capability of the IT department has a positive effect on PIM

HIT quality might be a function of the organization-wide climate toward IT. Such climate might also facilitate a stronger effect of the technical HIT quality (ie, the WCS) on the perceived quality of information provision

- H12: Organization-wide innovation capability has a positive effect on the WCS

- H13: Organization-wide innovation capability has a positive effect on the perceived HIT workflow support

- H14: Organization-wide innovation capability has a positive effect on the overall goodness of information provision

- H15: Organization-wide innovation capability positively moderates the relationship between the WCS and the overall goodness of information provision

Structural characteristics might be linked to HIT quality, possibly also to the TMT's capabilities to innovate

- H16: Structural characteristics have a positive effect on the WCS

[58], Fadol et al (2015) [87], Kruse et al (2014) [88], Troilo et al (2014) [89]

- H17: Structural characteristics have a positive effect on PIM

- H18: Structural characteristics have a positive effect on the innovation capability: top management team support

Compared with Germany, hospitals from Austria and Switzerland exhibit higher degrees of HIT workflow support and a more pronounced culture toward innovation

Bradley et al (2012) [71], Liebe et al (2018) [81], Weintraub and McKee (2019) [82]

Esdar et al (2018) [38], Paré et al (2020) [56], Leidner et al (2010) [54]

Liebe et al (2017) [83], Watts and Henderson [84]

Caccia-Bava et al (2006) [45], Gagnon et al (2012) [85], Taylor et al (2015) [86], Vest et al (2019) [50]

Esdar et al (2018) [38], Haux et al (2018) [90], Hübner et al (2010) [91], Hüsers et al (2017) [49], Naumann et al (2019) [11]

- H19: Country has a positive effect on the WCS

- H20: Country has a positive effect on organization-wide innovation capability

- H21: Country has a positive effect on the innovation capability of the IT department

aPIM: professionalism of information management. 
${ }^{\mathrm{b}}$ HIT: health information technology.

${ }^{\mathrm{c}}$ WCS: Workflow Composite Score.

${ }^{\mathrm{d}}$ IT: information technology.

\section{Parameter Estimations and Model Assessment}

We applied partial least squares structural equation modeling using SmartPLS version 3 [92]. The measurement models were assessed for internal consistency using Cronbach $\alpha$ and composite reliability. Convergent and discriminant validity was evaluated according to the height of the outer loadings, the average variance extracted, the Fornell-Larcker criterion, and the Heterotrait-Monotrait ratio.

Inner variance inflation factor values were used to test for collinearity within the structural model. Path coefficients and mediation effects were evaluated based on the direct, total, and indirect effects as well as on $\mathrm{f}^{2}$ effect sizes with $P$ values and 95\% CIs obtained from 10,000 bootstrap replications. Besides the $R^{2}$ values for the endogenous latent variables, we used

Table 3. Demographic characteristics of participating hospitals ( $N=232)$.

\begin{tabular}{ll}
\hline Characteristics & Value \\
\hline Country, $\mathbf{n}($ response rate in \%) & $14(8.8)$ \\
Austria & $205(18.3)$ \\
Germany & $13(11.3)$ \\
Switzerland & \\
Ownership, $\mathbf{n}$ (\% in sample) & $42(18.1)$ \\
For-profit & $78(33.6)$ \\
$\quad$ Nonprofit & $112(48.3)$ \\
Public & $22(9.5)$ \\
Teaching status, $\mathbf{n}$ (\% in sample) & $101(43.5)$ \\
Major teaching hospital & $109(47.0)$ \\
Minor teaching hospital & \\
Nonteaching hospital & $140(60.3)$ \\
Member of a hospital group, $\mathbf{n}(\%$ in sample) & $92(39.7)$ \\
Yes & $491.9(238.5)$ \\
No & \\
Number of beds, mean (SD) & \\
\hline
\end{tabular}

\section{Structural Equation Model}

The parameters assessing the measurement models pointed to valid specifications of the reflective models as well as the formative model in terms of convergent validity and internal consistency (Multimedia Appendices 4 and 5). In addition, sufficient discriminant validity was established according to the Fornell-Larcker criterion assessment, as indicated by the Heterotrait-Monotrait ratios of the correlations that were all below the recommended threshold value of 0.85 [93] (Multimedia Appendix 6). No collinearity was found in the structural model, as all the inner variance inflation factor values blindfolding to obtain Stone-Geisser $\mathrm{Q}^{2}$ values to determine the cross-validated predictive relevance of the exogenous constructs.

\section{Results}

\section{Descriptive Statistics}

The sample consisted of data from 232 hospitals, most of which were from Germany (Table 3), which corresponds to the higher baseline number of German hospitals. The participating hospitals were rather large, with an average size of 492 (SD 239) beds, and many $(112 / 232,48.3 \%)$ were in public ownership. Nevertheless, hospitals from all relevant demographic categories were included in the sample. The WCS, as the central measure of HIT workflow support in our model, showed an overall mean value of 56 (SD 14) points (ranging between 0 and 100 points; Multimedia Appendix 3). The mean values and SD of the remaining constructs are shown in Multimedia Appendix 1. ranged within the limits of 0.20 and 4. Moreover, the Stone-Geisser $\mathrm{Q}^{2}$ values of the endogenous variables indicate a good out-of-sample predictive power of the path model, especially with regard to the WCS $\left(\mathrm{Q}^{2}=0.38\right)$ and the overall goodness of information provision $\left(\mathrm{Q}^{2}=0.40\right)$.

The 21 hypotheses (Table 2) led to a variety of interrelationships in the structural model in terms of direct, mediated, and moderated effects. Approximately $50 \%$ of the variance in the key constructs for measuring HIT quality, the HIT workflow support (as measured by the WCS), and the perceived overall goodness of information provision (OGIP) could be explained by the model (Figure 2). 
Figure 2. The structural model of innovation and quality of health information technology with path coefficients, explained variance $\left(\mathrm{R}^{2}\right)$, and predictive relevance measures $\left(\mathrm{Q}^{2}\right)$ of the endogenous constructs. Latent constructs are displayed with rounded edges, the exogenous covariates as ellipses and the moderator variable with a cut-off corner. $* P<.05 ; * * P<.01$. HIT: health information technology.

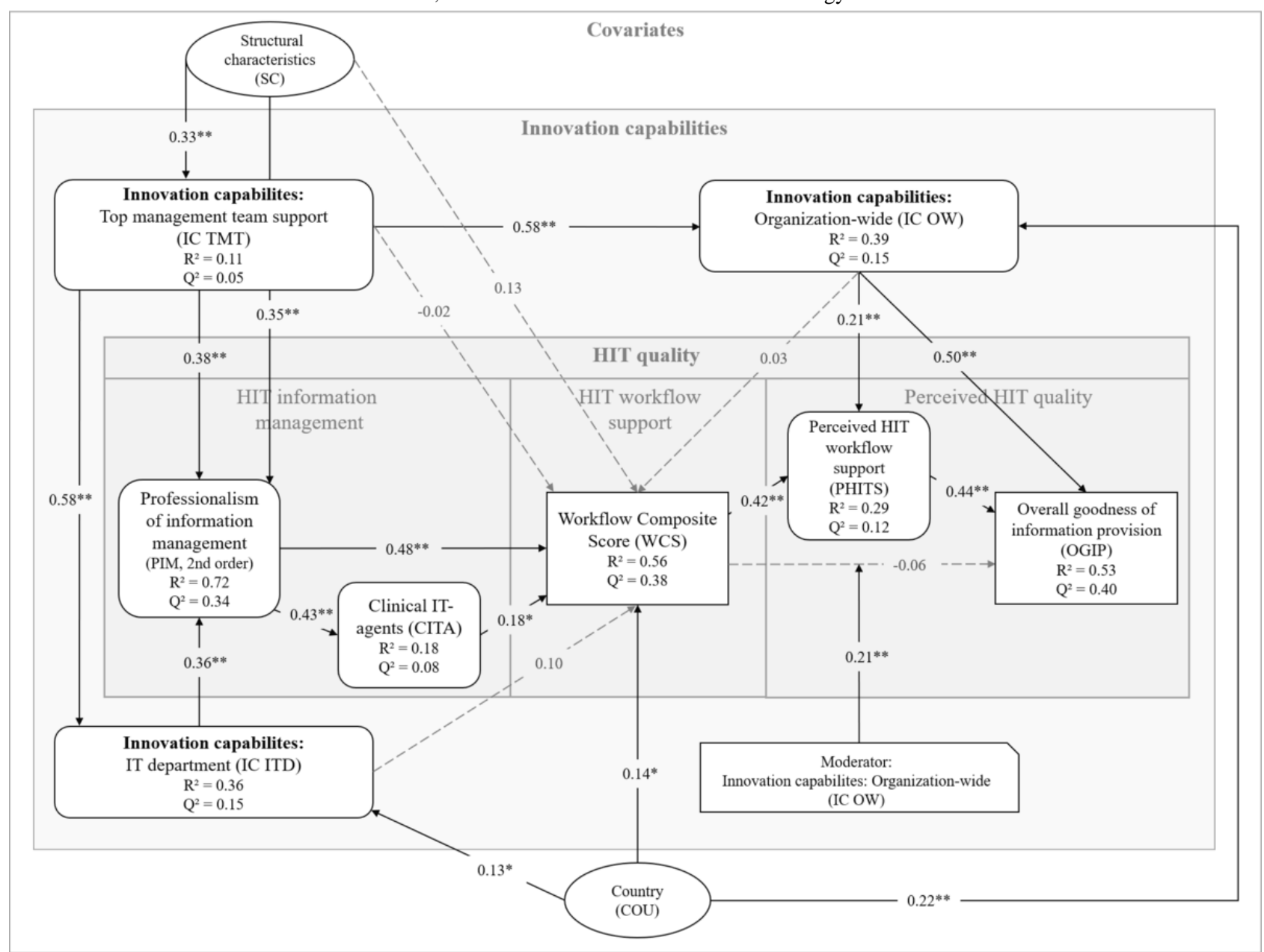

Within the HIT quality domain, the results showed a strong effect of PIM on the WCS with a path coefficient estimate of $0.48(P<.001)$. This association was partially mediated by the use of clinical IT agents to a small but significant extent (Multimedia Appendix 7). Furthermore, WCS was associated with OGIP via an indirect effect between the 2 , which was mediated by the perceived HIT workflow support. The exact $P$ values of the path coefficients are shown in Multimedia Appendix 8.

Within the innovation layer, the IC TMT exhibited a strong effect on IC ITD and IC OW.

Furthermore, the model revealed a strong association between innovation and quality at various levels (the total and indirect effects are given in Multimedia Appendix 7): the ICs of the
TMT and of the IT department significantly and similarly affected PIM, whereas IC OW had a strong effect on the perceived HIT quality in terms of OGIP and a weaker but still significant effect related to perceived HIT workflow support. Contrary to some of our initial assumptions, as expressed in hypotheses $\mathrm{H} 9, \mathrm{H} 10$, and H12, there was no significant direct effect of any of the constructs representing IC on the WCS (Table 4). Instead, the results showed significant indirect effects of IC TMT and IC ITD on the WCS mediated by PIM (Multimedia Appendix 7). The effect of the WCS on OGIP, which did not become significant, was, however, significantly moderated by IC OW (hypothesis H15). In summary, ICs possessed many points of application at the HIT quality path, that is, at the beginning influencing PIM and later affecting the overall quality of information provision for patient care. 
Table 4. Summarized results of the hypothesis tests in reference to $P$ values <.05.

\begin{tabular}{|c|c|}
\hline Hypothesis & Support by the model \\
\hline H1: PIM ${ }^{\mathrm{a}}$ has a positive effect on the WCS ${ }^{\mathrm{b}}$ & Supported \\
\hline H2: The effect of PIM on the WCS is partly mediated by clinical IT $^{\mathrm{c}}$ agents & Supported \\
\hline H3: The WCS has a positive effect on perceived HIT ${ }^{\mathrm{d}}$ workflow support & Supported \\
\hline H4: The WCS has a positive effect on the overall goodness of information provision & Not supported \\
\hline H5: Perceived HIT workflow support has a positive effect on the overall goodness of information provision & Supported \\
\hline H6: Innovation capabilities: Top management team support has a positive effect on organization-wide innovation capability & Supported \\
\hline $\begin{array}{l}\text { H7: Innovation capabilities: Top management team support has a positive effect on the innovation capability of the IT de- } \\
\text { partment }\end{array}$ & Supported \\
\hline H8: Innovation capabilities: Top management team support has a positive effect on PIM & Supported \\
\hline H9: Innovation capabilities: Top management team support has a positive effect on the WCS & Not supported \\
\hline H10: Innovation capability of the IT department has a positive effect on the WCS & Not supported \\
\hline H11: Innovation capability of the IT department has a positive effect on PIM & Supported \\
\hline H12: Organization-wide innovation capability has a positive effect on the WCS & Not supported \\
\hline H13: Organization-wide innovation capability has a positive effect on perceived HIT workflow support & Supported \\
\hline H14: Organization-wide innovation capability has a positive effect on the overall goodness of information provision & Supported \\
\hline $\begin{array}{l}\text { H15: Organization-wide innovation capability positively moderates the relationship between the WCS and the overall } \\
\text { goodness of information provision }\end{array}$ & Supported \\
\hline H16: Structural characteristics have a positive effect on the WCS & Not supported \\
\hline H17: Structural characteristics have a positive effect on PIM & Supported \\
\hline H18: Structural characteristics have a positive effect on innovation capabilities: top management team support & Supported \\
\hline H19: Country has a positive effect on the WCS & Supported \\
\hline H20: Country has a positive effect on the organization-wide innovation capability & Supported \\
\hline H21: Country has a positive effect on the innovation capability of the IT department & Supported \\
\hline
\end{tabular}

${ }^{\mathrm{a}} \mathrm{PIM}$ : professionalism of information management.

${ }^{b}$ WCS: Workflow Composite Score.

${ }^{\mathrm{c}}$ IT: information technology.

${ }^{\mathrm{d}}$ HIT: health information technology.

With regard to the covariates, the country had a significant effect on the WCS and was also associated with higher degrees of IC ITD and IC TMT, albeit with rather small effect sizes $\mathrm{f}^{2}$ (Multimedia Appendix 8). The organization's structural characteristics did not exhibit a direct effect on the WCS in our model but instead on the preceding latent variables in the model, namely, PIM and IC TMT.

\section{Discussion}

\section{Principal Findings}

On the basis of data from 232 hospitals in Austria, Germany, and Switzerland, a sociotechnical $\mathrm{IQ}_{\mathrm{HIT}}$ model was developed and tested. To the best of our knowledge, this is the first model that investigates HIT quality in light of the organizations' ability to innovate. It does so in a strictly empirical manner using a validated instrument. The model sets out the internal composition of HIT quality in establishing a consecutive connection between HIT information management, HIT workflow support, and perceived quality. Furthermore, an organization's ICs were positively associated with HIT quality at various levels. Most notably, an innovation-friendly attitude on the TMT level appeared to strongly but indirectly facilitate HIT-based workflow support, mediated by professional information management practices.

\section{The Inner Workings of HIT Quality}

At the core of the $\mathrm{IQ}_{\mathrm{HIT}}$ model, the WCS was used to measure HIT quality in terms of the workflow to support the IT solutions provided for improving patient care. The WCS is a multifaceted indicator that consists of a plethora of underlying items (Multimedia Appendix 2). By incorporating it, the model considers the complexity of interdepartmental and multifunctional health information systems.

According to the model, HIT workflow support depends on professional information management, that is, professionally conceptualized and performed activities at the strategic, tactical, and operational levels, as has been conjectured by Winter et al [34] and empirically conceptualized by Thye et al [36]. Only the HIT workflow support that is managed in an orderly and 
professional manner by the IT department can work properly regarding data and information provision, IT functions in place, their integration with one another, and the ability to distribute the data and the information to the point of care. Part of this effect is mediated by the presence of clinical IT agents, confirming the importance of establishing a formal link between IT department information management and clinical end users. Interestingly, the structural characteristics (bed count and teaching status) did not affect the HIT workflow support directly but only via the mediating effect of professional information management. This is rather surprising, as most studies suggest a direct link, particularly between the size of an organization and its HIT use [25].

HIT quality was conceptualized to encompass both, a technical component that bundles manifest, self-reported attributes about the information system, that is, the WCS, and a subjective judgment about its perceived quality. According to the CIOs' viewpoint, the very abstract judgment of the perceived goodness of information provision appears to not be directly linked to the WCS but requires some intermediate interpretation, that is, the perceived HIT workflow support, which refers to a more detailed perspective of admission, ward rounds, presurgery and postsurgery, and discharge processes. This also suggests that there is no strict automatism between a high degree of HIT quality in terms of its technical components and the perceived quality of information provision in an organization. This points to the need for good implementation practices of HIT interventions to successfully reap their benefits.

\section{Innovation Capabilities in Health Care Organizations}

The $\mathrm{IQ}_{\mathrm{HIT}}$ model also specifies the inner fabric of organizational IC. The underlying scales yielded good psychometric properties and reflected an innovation-friendly attitude and behavior at different organizational levels: at the executive level (IC TMT), the items mirror the motivational and monetary support of the TMT for IT innovation and their proactive engagement with respective projects as part of the organization's vision. Similar to the views in the Upper Echelons Theory, which stresses the crucial role of senior leadership in fostering innovation, this factor had a strong predictive relevance across the model [94]. IC ITD reflect the kind of CIO leadership that facilitates creativity, communication, and participation of end users. On the third level (IC OW), openness and widespread flexibility for embracing new IT solutions that prevail throughout the organization at large were the defining elements. Most of these characteristics were suspected [47,95,96] and partly known $[27,97,98]$ to facilitate innovation in a variety of contexts; however, the way they statistically cluster along different organizational levels and their different effects has not been specified before. Therefore, the innovative capacity of health organizations cannot be viewed as monolithic blocks or mere buzzwords. Its contents are woven throughout various organizational levels to varying degrees.

This study did not explicitly focus on how these capabilities can be built or how they are determined. However, when controlling for the covariates, we found that TMT support is a function of certain structural characteristics, namely, a higher bed count and teaching status, both of which can be interpreted as indicators of greater financial flexibility in terms of slack resources. However, ICs at the IT department and the organization at large depend on the respective country. More precisely, these 2 domains are more pronounced in Austria and Switzerland than in Germany, which corresponds well with previous findings on different samples $[11,49]$.

\section{HIT Implementation Between Innovation and Quality}

Traditionally, empirical research conducted on HIT quality has frequently disregarded aspects of innovation, and both have often been discussed separately from one another [75]. Our model establishes a connection between the two by showing that attaining high levels of HIT quality is facilitated and mediated by an organization's ability to create space for creativity, agility, and communication in relation to IT-based innovation.

Overall, the structural model (Figure 2) can be translated into a more schematic model (Figure 3) based on the major findings. It shows that PIM mediates the effects of the 2 IC domains-IC TMT and IC ITD—on HIT workflow support, which illustrates the interplay between the right attitude toward innovation and formalized management practices for innovational strength. The attitude and intent to innovate play an important role in and of itself; however, professional information management is needed for the practical execution of this intention to improve HIT workflow support. 
Figure 3. The innovation and quality of health information technology model. HIT: health information technology; IT: information technology.

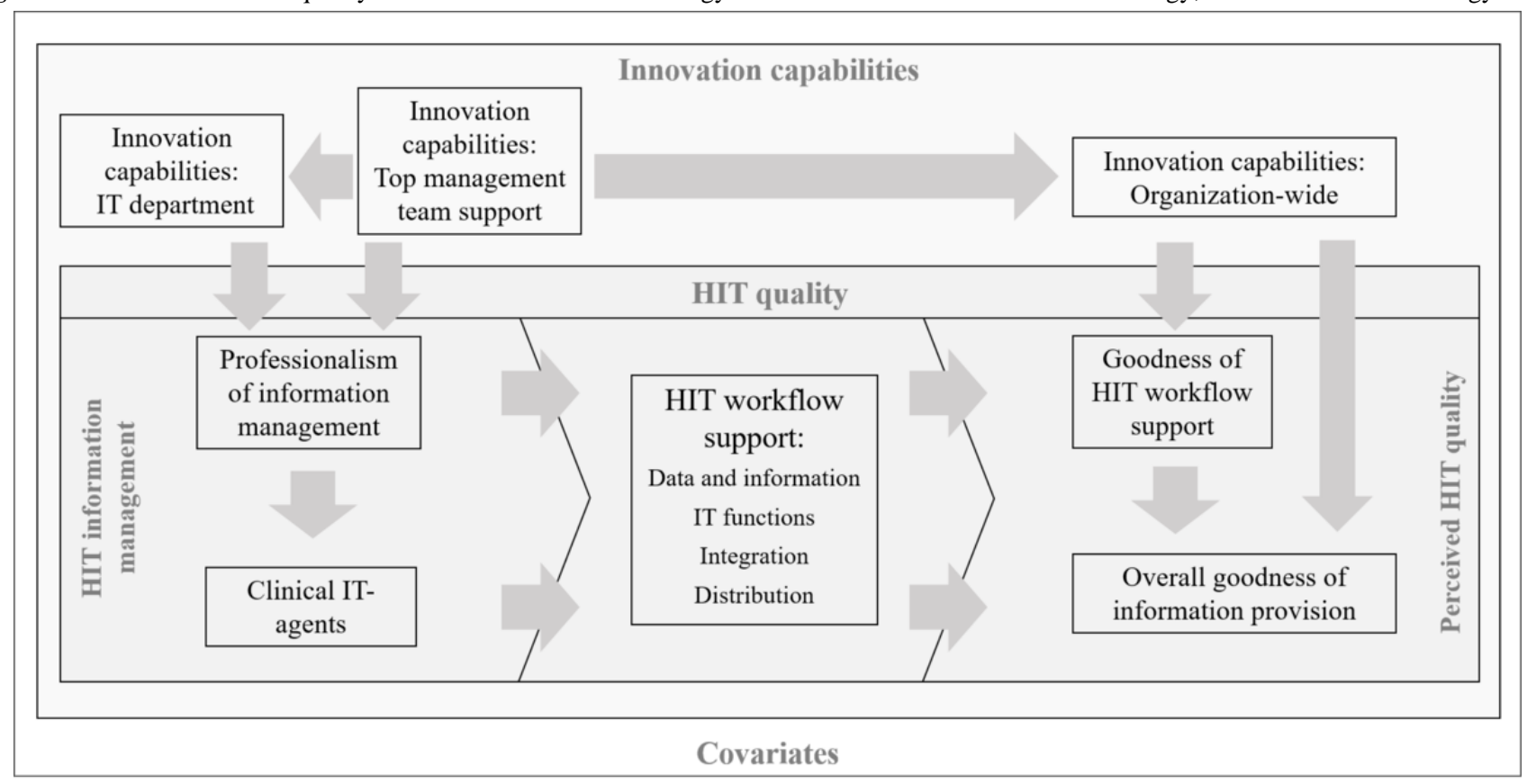

Furthermore, we found IC OW to partly moderate the relationship between the HIT workflow support and the perceived OGIP, implying that there might actually be a direct effect between the 2 as long as the organization is agile, flexible, and open toward IT (equals high levels of IC OW). This could be interpreted as an indication that an organization-wide positive attitude toward using the IT in place, irrespective of how advanced it actually is, leads to better information provision in the clinical care processes, at least from the vantage point of CIOs. Overall, it becomes clear that ICs are not only needed at the TMT level but also at the IT department level and throughout the organization to establish high-quality HIT solutions. Executive managers and policy makers should therefore consider how to establish higher levels of these capabilities at various levels.

\section{Limitations}

Our study had several limitations. Most notably, this is an observational study, and despite the statistical specifications that might suggest otherwise, it cannot be inferred that the relationship between constructs is truly causal. For instance, there might be temporal displacements between the current beliefs of executives and higher degrees of HIT quality as implementation processes take time [99].

Furthermore, this sociotechnical model reflects the perspective of the CIOs and their points of view of the HIT cosmos and ICs. This is both a strength and a weakness. The strength is its consistency and authenticity regarding technical and organizational issues related to IT. Its weakness is the CIOs cannot accurately evaluate clinicians' view on the timely and correct provision of data and information (ie, the right side of the model), which requires a more detailed assessment in future research. Ultimately, the clinical outcome is the improvement or stabilization of the patient's condition. None of this is captured in this model, as it mirrors the vantage point of CIOs.
The next step will be to develop a model that incorporates the views of physicians and nurses. This approach can also cope with potential common-method biases. The sample is also based on voluntary participation, which is why we cannot rule out a nonresponse bias in the data.

Finally, not all possibly relevant factors at play can be accurately accounted for in one model, which is reflected by the $\mathrm{R}^{2}$ values that leave parts of the variance in the endogenous constructs unexplained. Given these limitations, further studies are needed to validate and differentiate the relationships between and within IC and HIT quality, and our model provides various access points to do so.

\section{Conclusions}

On the basis of survey data provided by the CIOs of 232 hospitals, we proposed a sociotechnical $\mathrm{IQ}_{\mathrm{HIT}}$ model to explain how organizational innovation relates to various facets of HIT quality. Although some associations in the model could be presumed by the literature, it clearly and uniquely highlights the key role of ICs and information management for HIT-based workflow support. Thus, it demonstrates that innovation and quality do not contradict each other. In particular, an innovation-friendly attitude of TMT and the IT department determines the degree of HIT workflow support, albeit not directly, but by means of professional information management practices that eventually facilitate the perceived goodness of information provision for patient care. This suggests that managers of health organizations should strive for both a more pronounced culture toward innovation and professional information management to translate such a culture into HIT quality. Furthermore, the $\mathrm{IQ}_{\mathrm{HIT}}$ model might be useful for studies on HIT adoption and diffusion and for the definition of HIT maturity models. To this end, it provides validated measurement scales that can be utilized in future research. 


\section{Acknowledgments}

This study was funded by the State of Lower Saxony, Germany (grant number ZN 3103).

\section{Authors' Contributions}

UH initiated the study; ME, UH, and JL specified the theoretical framework, supported by BB, and conceptualized the research design. All authors were responsible for the scale development. ME, JL, and JT collected and prepared the data, supervised by UH, and assisted by several members of the Health Informatics Research Group of the University of Applied Sciences Osnabrück. ME specified the model and conducted the statistical analysis. ME and UH wrote the manuscript that was reviewed and approved by all authors.

\section{Conflicts of Interest}

None declared.

\section{Multimedia Appendix 1}

Measurement models and underlying items (questionnaire part A).

[DOCX File, 22 KB-Multimedia Appendix 1]

\section{Multimedia Appendix 2}

Workflow Composite Score (WCS): structure and underlying items (questionnaire part B).

[XLSX File (Microsoft Excel File), 22 KB-Multimedia Appendix 2]

\section{Multimedia Appendix 3}

Descriptive statistics of the Workflow Composite Score (WCS; $\mathrm{n}=232$ ).

[DOCX File, 14 KB-Multimedia Appendix 3]

\section{Multimedia Appendix 4}

Convergent validity and internal consistency of the measurement models with bias corrected $95 \%$ CIs.

[DOCX File, 17 KB-Multimedia Appendix 4]

\section{Multimedia Appendix 5}

Convergent validity and internal consistency of lower order constructs reflecting the latent variable "Professionalism of Information Management (PIM)" with bias corrected 95\% CIs.

[DOCX File, 16 KB-Multimedia Appendix 5]

\section{Multimedia Appendix 6}

Heterotrait-Monotrait (HTMT) ratios.

[DOCX File, 15 KB-Multimedia Appendix 6]

\section{Multimedia Appendix 7}

Total effects and total indirect effects of the structural model with bias corrected $95 \%$ CIs and significance tests of the path coefficients.

[DOCX File, 17 KB-Multimedia Appendix 7]

\section{Multimedia Appendix 8}

Direct path coefficients with bias corrected $95 \%$ CIs, significance tests of path coefficients, and their effect sizes. [DOCX File, 16 KB-Multimedia Appendix 8]

\section{References}

1. Thouin MF, Hoffman JJ, Ford EW. The effect of information technology investment on firm-level performance in the health care industry. Health Care Manage Rev 2008;33(1):60-68. [doi: 10.1097/01.HMR.0000304491.03147.06] [Medline: $\underline{18091445]}$ 
2. Driessen J, Cioffi M, Alide N, Landis-Lewis Z, Gamadzi G, Gadabu OJ, et al. Modeling return on investment for an electronic medical record system in Lilongwe, Malawi. J Am Med Inform Assoc 2013;20(4):743-748 [FREE Full text] [doi: 10.1136/amiajnl-2012-001242] [Medline: 23144335]

3. Ross J, Stevenson F, Lau R, Murray E. Factors that influence the implementation of e-health: a systematic review of systematic reviews (an update). Implement Sci 2016 Oct 26;11(1):146 [FREE Full text] [doi: 10.1186/s13012-016-0510-7] [Medline: 27782832]

4. Yen PY, McAlearney AS, Sieck CJ, Hefner JL, Huerta TR. Health information technology (HIT) adaptation: refocusing on the journey to successful HIT implementation. JMIR Med Inform 2017 Sep 07;5(3):e28 [FREE Full text] [doi: 10.2196/medinform.7476] [Medline: 28882812]

5. Cresswell KM, Sheikh A. Health information technology in hospitals: current issues and future trends. Future Hosp J 2015 Feb;2(1):50-56 [FREE Full text] [doi: 10.7861/futurehosp.2-1-50] [Medline: 31098079]

6. Desveaux L, Soobiah C, Bhatia RS, Shaw J. Identifying and overcoming policy-level barriers to the implementation of digital health innovation: qualitative study. J Med Internet Res 2019 Dec 20;21(12):e14994 [FREE Full text] [doi: 10.2196/14994] [Medline: $\underline{31859679]}$

7. Kruse CS, Beane A. Health information technology continues to show positive effect on medical outcomes: systematic review. J Med Internet Res 2018 Feb 05;20(2):e41 [FREE Full text] [doi: 10.2196/jmir.8793] [Medline: 29402759]

8. Lin SC, Jha AK, Adler-Milstein J. Electronic health records associated with lower hospital mortality after systems have time to mature. Health Aff (Millwood) 2018 Jul;37(7):1128-1135. [doi: 10.1377/hlthaff.2017.1658] [Medline: 29985687]

9. Plantier M, Havet N, Durand T, Caquot N, Amaz C, Philip I, et al. Does adoption of electronic health records improve organizational performances of hospital surgical units? Results from the French e-SI (PREPS-SIPS) study. Int J Med Inform 2017 Feb;98:47-55. [doi: 10.1016/j.ijmedinf.2016.12.002] [Medline: 28034412]

10. Asthana S, Jones R, Sheaff R. Why does the NHS struggle to adopt eHealth innovations? A review of macro, meso and micro factors. BMC Health Serv Res 2019 Dec 21;19(1):984 [FREE Full text] [doi: 10.1186/s12913-019-4790-x] [Medline: $\underline{31864370]}$

11. Naumann L, Esdar M, Ammenwerth E, Baumberger D, Hübner U. Same goals, yet different outcomes: analysing the current state of eHealth adoption and policies in Austria, Germany, and Switzerland using a mixed methods approach. Stud Health Technol Inform 2019 Aug 21;264:1012-1016. [doi: 10.3233/SHTI190377] [Medline: 31438077]

12. Cresswell K, Sheikh A. Organizational issues in the implementation and adoption of health information technology innovations: an interpretative review. Int J Med Inform 2013 May;82(5):e73-e86. [doi: 10.1016/j.ijmedinf.2012.10.007] [Medline: 23146626]

13. Kim YG, Jung K, Park YT, Shin D, Cho SY, Yoon D, et al. Rate of electronic health record adoption in South Korea: a nation-wide survey. Int J Med Inform 2017 May;101:100-107. [doi: 10.1016/j.ijmedinf.2017.02.009] [Medline: 28347440]

14. Piening EP. Insights into the process dynamics of innovation implementation. Pub Manage Rev 2011 Jan;13(1):127-157. [doi: 10.1080/14719037.2010.501615]

15. Colicchio TK, Cimino JJ, Del Fiol G. Unintended consequences of nationwide electronic health record adoption: challenges and opportunities in the post-meaningful use era. J Med Internet Res 2019 Jun 03;21(6):e13313 [FREE Full text] [doi: 10.2196/13313] [Medline: 31162125]

16. Sabes-Figuera R, Maghiros I. European hospital survey: benchmarking deployment of e-Health services (2012-2013). Luxembourg: Publications Office of the European Union; 2013:978-992.

17. Liebe JD, Hübner U, Straede MC, Thye J. Developing a workflow composite score to measure clinical information logistics. A top-down approach. Methods Inf Med 2015;54(5):424-433. [doi: 10.3414/ME14-02-0025] [Medline: 26419492]

18. Martin G, Clarke J, Liew F, Arora S, King D, Aylin P, et al. Evaluating the impact of organisational digital maturity on clinical outcomes in secondary care in England. NPJ Digit Med 2019;2:41 [FREE Full text] [doi: 10.1038/s41746-019-0118-9] [Medline: $\underline{31304387]}$

19. Greenhalgh T, Wherton J, Papoutsi C, Lynch J, Hughes G, A'Court C, et al. Beyond adoption: a new framework for theorizing and evaluating nonadoption, abandonment, and challenges to the scale-up, spread, and sustainability of health and care technologies. J Med Internet Res 2017 Nov 01;19(11):e367 [FREE Full text] [doi: 10.2196/jmir.8775] [Medline: 29092808]

20. Damschroder LJ, Aron DC, Keith RE, Kirsh SR, Alexander JA, Lowery JC. Fostering implementation of health services research findings into practice: a consolidated framework for advancing implementation science. Implement Sci 2009 Aug 07;4:50 [FREE Full text] [doi: 10.1186/1748-5908-4-50] [Medline: 19664226]

21. Rogers EM. Diffusion of innovations. Fifth edition. New York: Free Press; 2003.

22. Tornatzky LG, Fleischer M. The processes of technological innovation. Maryland, United States: Lexington Books; 1990.

23. Yusof MM, Kuljis J, Papazafeiropoulou A, Stergioulas LK. An evaluation framework for Health Information Systems: human, organization and technology-fit factors (HOT-fit). Int J Med Inform 2008 Jun;77(6):386-398. [doi: 10.1016/j.ijmedinf.2007.08.011] [Medline: 17964851]

24. Lau F, Price M, Keshavjee K. From benefits evaluation to clinical adoption: making sense of health information system success in Canada. Healthc Q 2011;14(1):39-45. [doi: 10.12927/hcq.2011.22157] [Medline: 21301238]

25. Kruse CS, Kothman K, Anerobi K, Abanaka L. Adoption factors of the electronic health record: a systematic review. JMIR Med Inform 2016 Jun 01;4(2):e19 [FREE Full text] [doi: 10.2196/medinform.5525] [Medline: 27251559] 
26. Sligo J, Gauld R, Roberts V, Villa L. A literature review for large-scale health information system project planning, implementation and evaluation. Int J Med Inform 2017 Jan;97:86-97. [doi: 10.1016/j.ijmedinf.2016.09.007] [Medline: 27919399]

27. Ben-Zion R, Pliskin N, Fink L. Critical success factors for adoption of electronic health record systems: literature review and prescriptive analysis. Info Sys Manage 2014 Oct 28;31(4):296-312. [doi: 10.1080/10580530.2014.958024]

28. Schreiweis B, Pobiruchin M, Strotbaum V, Suleder J, Wiesner M, Bergh B. Barriers and facilitators to the implementation of eHealth services: systematic literature analysis. J Med Internet Res 2019 Nov 22;21(11):e14197 [FREE Full text] [doi: 10.2196/14197] [Medline: 31755869]

29. Brenner SK, Kaushal R, Grinspan Z, Joyce C, Kim I, Allard RJ, et al. Effects of health information technology on patient outcomes: a systematic review. J Am Med Inform Assoc 2016 Sep;23(5):1016-1036 [FREE Full text] [doi: 10.1093/jamia/ocv138] [Medline: 26568607]

30. Häyrinen K, Saranto K, Nykänen P. Definition, structure, content, use and impacts of electronic health records: a review of the research literature. Int J Med Inform 2008 May;77(5):291-304. [doi: 10.1016/j.ijmedinf.2007.09.001] [Medline: 17951106]

31. Everson J, Lee SD, Friedman CP. Reliability and validity of the American Hospital Association's national longitudinal survey of health information technology adoption. J Am Med Inform Assoc 2014 Oct;21(e2):e257-e263 [FREE Full text] [doi: 10.1136/amiajnl-2013-002449] [Medline: 24623194]

32. Pettit L. Understanding EMRAM and how it can be used by policy-makers, hospital CIOs and their IT teams. World Hosp Health Serv 2013;49(3):7-9. [Medline: 24377140]

33. Carvalho JV, Rocha A, Abreu A. Maturity models of healthcare information systems and technologies: a literature review. J Med Syst 2016 Jun;40(6):131. [doi: 10.1007/s10916-016-0486-5] [Medline: 27083575]

34. Winter A, Takabayashi K, Jahn F, Kimura E, Engelbrecht R, Haux R, et al. Quality requirements for electronic health record systems. A Japanese-German information management perspective. Methods Inf Med 2017 Aug 07;56(7):e92-e104 [FREE Full text] [doi: 10.3414/ME17-05-0002] [Medline: 28925415]

35. Ammenwerth E, Ehlers F, Hirsch B, Gratl G. HIS-Monitor: an approach to assess the quality of information processing in hospitals. Int J Med Inform 2007;76(2-3):216-225. [doi: 10.1016/j.ijmedinf.2006.05.004] [Medline: $\underline{16777476]}$

36. Thye J, Esdar M, Liebe J, Jahn F, Winter A, Hübner U. Professionalism of information management in health care: development and validation of the construct and its measurement. Methods Inf Med 2020 Jun;59(S 01):e1-e12 [FREE Full text] [doi: 10.1055/s-0040-1712465] [Medline: $\underline{32620017]}$

37. Adler-Milstein J, Woody Scott K, Jha AK. Leveraging EHRs to improve hospital performance: the role of management. Am J Manag Care 2014 Nov;20(11 Spec No. 17):SP511-SP519 [FREE Full text] [Medline: 25811825]

38. Esdar M, Liebe J, Babitsch B, Hübner U. Determinants of clinical information logistics: tracing socio-organisational factors and country differences from the perspective of clinical directors. Stud Health Technol Inform 2018;253:143-147. [Medline: 30147060]

39. Haux R. Health information systems - past, present, future. Int J Med Inform 2006;75(3-4):268-281. [doi: 10.1016/j.ijmedinf.2005.08.002] [Medline: 16169771]

40. Ingebrigtsen T, Georgiou A, Clay-Williams R, Magrabi F, Hordern A, Prgomet M, et al. The impact of clinical leadership on health information technology adoption: systematic review. Int J Med Inform 2014 Jun;83(6):393-405. [doi: 10.1016/j.ijmedinf.2014.02.005] [Medline: 24656180]

41. Pagliari C. Design and evaluation in eHealth: challenges and implications for an interdisciplinary field. J Med Internet Res 2007 May 27;9(2):e15 [FREE Full text] [doi: 10.2196/jmir.9.2.e15] [Medline: 17537718]

42. Liebe JD, Esdar M, Hübner U. Measuring the availability of electronic patient data across the hospital and throughout selected clinical workflows. Stud Health Technol Inform 2018;253:99-103. [Medline: 30147050]

43. Esdar M, Hübner U, Liebe J, Hüsers J, Thye J. Understanding latent structures of clinical information logistics: a bottom-up approach for model building and validating the workflow composite score. Int J Med Inform 2017 Jan;97:210-220. [doi: 10.1016/j.ijmedinf.2016.10.011] [Medline: 27919379]

44. van Gemert-Pijnen JEWC, Nijland N, van Limburg M, Ossebaard HC, Kelders SM, Eysenbach G, et al. A holistic framework to improve the uptake and impact of eHealth technologies. J Med Internet Res 2011 Dec 05;13(4):e111 [FREE Full text] [doi: 10.2196/jmir.1672] [Medline: 22155738]

45. Caccia-Bava MDC, Guimaraes T, Harrington SJ. Hospital organization culture, capacity to innovate and success in technology adoption. J Health Organ Manag 2006;20(2-3):194-217. [doi: 10.1108/14777260610662735] [Medline: 16869354]

46. Luu TT, Venkatesh S. Organizational culture and technological innovation adoption in private hospitals. Int Busi Res 2010 Jun 11;3(3):144. [doi: 10.5539/ibr.v3n3p144]

47. Wisdom JP, Chor KHB, Hoagwood KE, Horwitz SM. Innovation adoption: a review of theories and constructs. Adm Policy Ment Health 2014 Jul;41(4):480-502 [FREE Full text] [doi: 10.1007/s10488-013-0486-4] [Medline: 23549911]

48. Allen JD, Towne SD, Maxwell AE, DiMartino L, Leyva B, Bowen DJ, et al. Meausures of organizational characteristics associated with adoption and/or implementation of innovations: a systematic review. BMC Health Serv Res 2017 Aug 23;17(1):591 [FREE Full text] [doi: 10.1186/s12913-017-2459-x] [Medline: 28835273] 
49. Hüsers J, Hübner U, Esdar M, Ammenwerth E, Hackl WO, Naumann L, et al. Innovative power of health care organisations affects IT adoption: a bi-national health IT benchmark comparing Austria and Germany. J Med Syst 2017 Feb;41(2):33. [doi: 10.1007/s10916-016-0671-6] [Medline: 28054195]

50. Vest JR, Jung H, Wiley K, Kooreman H, Pettit L, Unruh MA. Adoption of health information technology among US nursing facilities. J Am Med Dir Assoc 2019 Aug;20(8):995-1000 [FREE Full text] [doi: 10.1016/j.jamda.2018.11.002] [Medline: $\underline{30579920}]$

51. Fernandez ME, Walker TJ, Weiner BJ, Calo WA, Liang S, Risendal B, et al. Developing measures to assess constructs from the Inner Setting domain of the Consolidated Framework for Implementation Research. Implement Sci 2018 Mar 27;13(1):52 [FREE Full text] [doi: 10.1186/s13012-018-0736-7] [Medline: 29587804]

52. Esdar M, Liebe J, Weiß JP, Hübner U. Exploring innovation capabilities of hospital CIOs: an empirical assessment. Stud Health Technol Inform 2017;235:383-387. [Medline: 28423819]

53. Tomlins JC. Is it possible for the NHS to become fully digital? In: Cons Informatics and Digi Health. Amsterdam: Springer; 2019:359-374.

54. Leidner DE, Preston D, Chen D. An examination of the antecedents and consequences of organizational IT innovation in hospitals. J Strateg Info Sys 2010 Sep;19(3):154-170. [doi: 10.1016/j.jsis.2010.07.002]

55. Faber S, van Geenhuizen M, de Reuver M. eHealth adoption factors in medical hospitals: a focus on the Netherlands. Int J Med Inform 2017 Apr;100:77-89. [doi: 10.1016/j.ijmedinf.2017.01.009] [Medline: 28241940]

56. Paré G, Guillemette MG, Raymond L. IT centrality, IT management model, and contribution of the IT function to organizational performance: a study in Canadian hospitals. Info and Manage 2020 Apr;57(3). [doi: 10.1016/j.im.2019.103198]

57. Greenhalgh T, Robert G, Macfarlane F, Bate P, Kyriakidou O. Diffusion of innovations in service organizations: systematic review and recommendations. Milbank Q 2004;82(4):581-629 [FREE Full text] [doi: 10.1111/j.0887-378X.2004.00325.x] [Medline: 15595944$]$

58. DesRoches CM, Worzala C, Joshi MS, Kralovec PD, Jha AK. Small, nonteaching, and rural hospitals continue to be slow in adopting electronic health record systems. Health Aff (Millwood) 2012 May;31(5):1092-1099. [doi: 10.1377/hlthaff.2012.0153] [Medline: 22535503]

59. Liebe JD, Egbert N, Frey A, Hübner U. Characteristics of German hospitals adopting health IT systems - results from an empirical study. Stud Health Technol Inform 2011;169:335-338. [Medline: 21893768]

60. Zhang NJ, Seblega B, Wan T, Unruh L, Agiro A, Miao L. Health information technology adoption in U.S. acute care hospitals. J Med Syst 2013 Apr;37(2):9907. [doi: 10.1007/s10916-012-9907-2] [Medline: 23340826]

61. Esdar M, Hüsers J, Weiß JP, Rauch J, Hübner U. Diffusion dynamics of electronic health records: a longitudinal observational study comparing data from hospitals in Germany and the United States. Int J Med Inform 2019 Nov;131:103952. [doi: 10.1016/j.ijmedinf.2019.103952] [Medline: 31557699]

62. Szydlowski S, Smith C. Perspectives from nurse leaders and chief information officers on health information technology implementation. Hosp Top 2009;87(1):3-9. [doi: 10.3200/HTPS.87.1.3-9] [Medline: 19103582]

63. Smaltz DH, Sambamurthy V, Agarwal R. The antecedents of CIO role effectiveness in Organizations: an empirical study in the healthcare sector. IEEE Trans Eng Manage 2006 May;53(2):207-222. [doi: 10.1109/tem.2006.872248]

64. IT-Report Healthcare 2020. Hübner U. URL: https://www.hs-osnabrueck.de/de/it-report-gesundheitswesen/ [accessed 2020-05-04]

65. Hübner U, Esdar M, Hüsers J, Liebe J, Rauch J, Thye J, et al. Status of digitization and the use of technology in German hospitals. In: Hospital Report 2019. Berlin, Heidelberg: Springer; 2019:33-48.

66. Weiß JP, Thye J, Rauch J, Tissen M, Esdar M, Teuteberg F, et al. IT benchmarking as an interaction between science and practice - a web portal for the dissemination of individual results for hospitals. In: Proceedings of the Multi-Conference of Information Systems 2018. 2018 Presented at: Multi-Conference of Information Systems 2018; March 2018; Lüneburg URL: https://tinyurl.com/9v4n4pxn

67. Hair J, Hult GTM, Ringle CM, Sarstedt M. A Primer on Partial Least Squares Structural Equation Modeling (PLS-SEM). Thousand Oaks, California, United States: Sage Publications Inc; 2017.

68. Becker JM, Klein K, Wetzels M. Hierarchical latent variable models in PLS-SEM: guidelines for using reflective-formative type models. Long Range Planning 2012 Oct;45(5-6):359-394. [doi: 10.1016/j.lrp.2012.10.001]

69. Ammenwerth E, Iller C, Mahler C. IT-adoption and the interaction of task, technology and individuals: a fit framework and a case study. BMC Med Inform Decis Mak 2006 Jan 09;6:3 [FREE Full text] [doi: 10.1186/1472-6947-6-3] [Medline: $\underline{16401336]}$

70. Avgar AC, Litwin AS, Pronovost PJ. Drivers and barriers in health IT adoption: a proposed framework. Appl Clin Inform 2012;3(4):488-500 [FREE Full text] [doi: 10.4338/ACI-2012-07-R-0029] [Medline: 23646093]

71. Bradley RV, Byrd TA, Pridmore JL, Thrasher E, Pratt RM, Mbarika VW. An empirical examination of antecedents and consequences of IT governance in us hospitals. J Info Tech 2012 Jun 01;27(2):156-177. [doi: 10.1057/jit.2012.3]

72. Winter A, Gardner RM. Health information systems: architectures and strategies. 2nd ed. Switzerland: Springer; 2011.

73. Potts HW, Keen J, Denby T, Featherstone I, Patterson D, Anderson J, et al. Towards a better understanding of delivering e-health systems: a systematic review using the meta-narrative method and two case studies: final report 2011. URL: http:/ /www.netscc.ac.uk/hsdr/files/project/SDO FR 08-1602-131 V01.pdf [accessed 2021-02-17] 
74. Hadji B, Degoulet P. Information system end-user satisfaction and continuance intention: a unified modeling approach. J Biomed Inform 2016 Jun;61:185-193 [FREE Full text] [doi: 10.1016/j.jbi.2016.03.021] [Medline: 27033175]

75. Hübner U. What are complex eHealth innovations and how do you measure them? Position paper. Methods Inf Med 2015;54(4):319-327. [doi: 10.3414/ME14-05-0001] [Medline: 25510406]

76. Gorla N, Somers TM, Wong B. Organizational impact of system quality, information quality, and service quality. J Strateg Info Sys 2010 Sep;19(3):207-228. [doi: 10.1016/j.jsis.2010.05.001]

77. Suki NM. Correlations of perceived flow, perceived system quality, perceived information quality, and perceived user trust on mobile social networking service (SNS) users' loyalty. J Inf Technol Res 2012;5(2):1-14. [doi: 10.4018/jitr.2012040101]

78. Abdekhoda M, Ahmadi M, Gohari M, Noruzi A. The effects of organizational contextual factors on physicians' attitude toward adoption of Electronic Medical Records. J Biomed Inform 2015 Feb;53:174-179 [FREE Full text] [doi: 10.1016/j.jbi.2014.10.008] [Medline: 25445481]

79. Carpenter MA, Geletkanycz MA, Sanders WG. Upper echelons research revisited: antecedents, elements, and consequences of top management team composition. J Manage 2016 Jun 23;30(6):749-778. [doi: 10.1016/j.jm.2004.06.001]

80. Laukka E, Huhtakangas M, Heponiemi T, Kanste O. Identifying the roles of healthcare leaders in hit implementation: a scoping review of the quantitative and qualitative evidence. Int J Environ Res Public Health 2020 Apr 21;17(8) [FREE Full text] [doi: 10.3390/ijerph17082865] [Medline: 32326300]

81. Liebe JD, Esdar M, Thye J, Hübner UH. Auf dem Weg zum digitalen Krankenhausine empirische Analyse über die gemeinsame Wirkung von Intrapreneurship und Informationsmanagement. In: Proceedings of the conference : Data driven X - Turning Data into Value. 2018 Presented at: Data driven X — Turning Data into Value; March 2018; Leuphana Universität Lüneburg.

82. Weintraub P, McKee M. Leadership for innovation in healthcare: an exploration. Int J Health Policy Manag 2019 Mar 01;8(3):138-144 [FREE Full text] [doi: 10.15171/ijhpm.2018.122] [Medline: 30980629]

83. Liebe JD, Esdar M, Thye J, Hübner U. Antecedents of CIOs' innovation capability in hospitals: results of an empirical study. Stud Health Technol Inform 2017;243:142-146. [Medline: 28883188]

84. Watts S, Henderson JC. Innovative IT climates: CIO perspectives. J Strateg Info Sys 2006 Jun;15(2):125-151. [doi: 10.1016/j.jsis.2005.08.001]

85. Gagnon MP, Desmartis M, Labrecque M, Car J, Pagliari C, Pluye P, et al. Systematic review of factors influencing the adoption of information and communication technologies by healthcare professionals. J Med Syst 2012 Feb;36(1):241-277 [FREE Full text] [doi: 10.1007/s10916-010-9473-4] [Medline: 20703721]

86. Taylor N, Clay-Williams R, Hogden E, Braithwaite J, Groene O. High performing hospitals: a qualitative systematic review of associated factors and practical strategies for improvement. BMC Health Serv Res 2015 Jun 24;15:244 [FREE Full text] [doi: 10.1186/s12913-015-0879-z] [Medline: 26104760]

87. Fadol Y, Barhem B, Elbanna S. The mediating role of the extensiveness of strategic planning on the relationship between slack resources and organizational performance. Manage Deci 2015 Jun 15;53(5):1023-1044. [doi: 10.1108/md-09-2014-0563]

88. Kruse CS, DeShazo J, Kim F, Fulton L. Factors associated with adoption of health information technology: a conceptual model based on a systematic review. JMIR Med Inform 2014 May 23;2(1):e9 [FREE Full text] [doi: 10.2196/medinform.3106] [Medline: 25599673]

89. Troilo G, De Luca LM, Atuahene-Gima K. More innovation with less? A strategic contingency view of slack resources, information search, and radical innovation. J Prod Innov Manag 2013 Oct 08;31(2):259-277. [doi: 10.1111/jpim.12094]

90. Haux R, Ammenwerth E, Koch S, Lehmann CU, Park H, Saranto K, et al. A brief survey on six basic and reduced eHealth indicators in seven countries in 2017. Appl Clin Inform 2018 Jul;9(3):704-713 [FREE Full text] [doi: 10.1055/s-0038-1669458] [Medline: 30184560]

91. Hübner U, Ammenwerth E, Flemming D, Schaubmayr C, Sellemann B. IT adoption of clinical information systems in Austrian and German hospitals: results of a comparative survey with a focus on nursing. BMC Med Inform Decis Mak 2010 Feb 02;10:8 [FREE Full text] [doi: 10.1186/1472-6947-10-8] [Medline: 20122275]

92. Ringle CM, Wende S, Becker JM. SmartPLS 3. URL: http://www.smartpls.com [accessed 2021-02-17]

93. Henseler J, Ringle CM, Sarstedt M. A new criterion for assessing discriminant validity in variance-based structural equation modeling. J Acad Mark Sci 2014 Aug 22;43(1):115-135. [doi: 10.1007/s11747-014-0403-8]

94. Hambrick DC, Mason PA. Upper echelons: the organization as a reflection of its top managers. Aca of Manage Rev 1984 Apr;9(2):193-206. [doi: 10.5465/amr.1984.4277628]

95. Paulus RA, Davis K, Steele GD. Continuous innovation in health care: implications of the Geisinger experience. Health Aff (Millwood) 2008;27(5):1235-1245. [doi: 10.1377/hlthaff.27.5.1235] [Medline: 18780906]

96. Patterson F, Kerrin M, Gatto-Roissard G. Characteristics and behaviours of innovative people in organisations. Literature review prepared for the NESTA Policy \& Research Unit. 2009. URL: https://media.nesta.org.uk/documents/ characteristics_behaviours_of_innovative_people.pdf [accessed 2021-02-17]

97. Elenkov DS, Judge W, Wright P. Strategic leadership and executive innovation influence: an international multi-cluster comparative study. Strat Mgmt J 2005 Jul;26(7):665-682. [doi: 10.1002/smj.469] 
98. Patel VM, Ashrafian H, Uzoho C, Nikiteas N, Panzarasa P, Sevdalis N, et al. Leadership behaviours and healthcare research performance: prospective correlational study. Postgrad Med J 2016 Nov;92(1093):663-669. [doi:

10.1136/postgradmedj-2016-134088] [Medline: 27190092]

99. McAlearney AS, Hefner JL, Sieck CJ, Huerta TR. The journey through grief: insights from a qualitative study of electronic health record implementation. Health Serv Res 2015 Apr;50(2):462-488 [FREE Full text] [doi: 10.1111/1475-6773.12227] [Medline: 25219627]

\author{
Abbreviations \\ CIO: chief information officer \\ HIT: health information technology \\ IT: information technology \\ IC: innovation capability \\ IC ITD: innovation capabilities at the information technology department level \\ IC TMT: innovation capabilities at the top management team level \\ IC OW: innovation capabilities at the organization-wide level \\ IQHIT: innovation and quality of HIT \\ OGIP: overall goodness of information provision \\ PIM: professionalism of information management \\ TMT: top management team \\ WCS: Workflow Composite Score
}

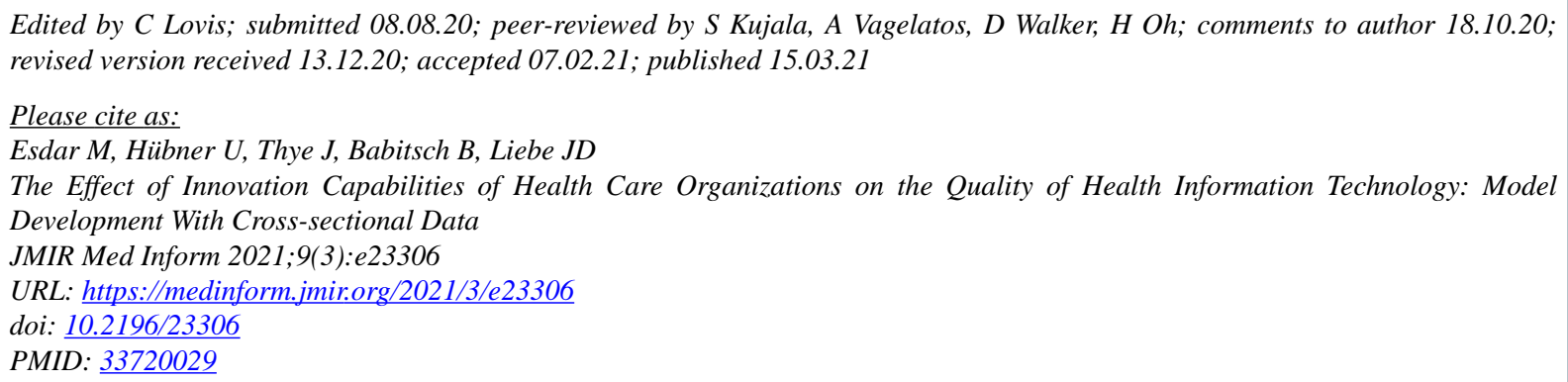

CMoritz Esdar, Ursula Hübner, Johannes Thye, Birgit Babitsch, Jan-David Liebe. Originally published in JMIR Medical Informatics (http://medinform.jmir.org), 15.03.2021. This is an open-access article distributed under the terms of the Creative Commons Attribution License (https://creativecommons.org/licenses/by/4.0/), which permits unrestricted use, distribution, and reproduction in any medium, provided the original work, first published in JMIR Medical Informatics, is properly cited. The complete bibliographic information, a link to the original publication on http://medinform.jmir.org/, as well as this copyright and license information must be included. 